\title{
Microwave-assisted Synthesis of Semiconductor Nanomaterials for Energy Storage
}

\author{
Haipeng $\mathrm{Chu}^{1}$, Xinjuan Liu ${ }^{1, *}$, Lengyuan $\mathrm{Niu}^{1}$, Can $\mathrm{Li}^{1}$, YinYan Gong ${ }^{1}$, Shiqiang $\mathrm{Li}^{3,{ }^{* *}}$ and \\ Chang Q. Sun ${ }^{2}$
}

\begin{abstract}
${ }^{1}$ Institute of Coordination Bond Metrology and Engineering, College of Materials Science and Engineering, China Jiliang University, Hangzhou 310018, P.R. China; ${ }^{2}$ Center for Coordination BondBand Engineering, School of Electrical and Electronic Engineering, Nanyang Technological University, Singapore, 639798, Singapore; ${ }^{3}$ Electrical and Electronic Engineering, Parkville, University of Melbourne 3010 Australia
\end{abstract}

\begin{abstract}
Semiconductor nanostructure has attracted tremendous attention due to its potential in electrochemical energy storage systems. The energy capacity is related to the properties of electrode materials. In this treatise, we will survey the recent advancement of the semiconductor nanostructures synthesized by microwave assisted method for electrode materials in electrochemical energy storage, and these nanostructures are found to show the improved electrochemical performance compared with the traditional synthesized methods.
\end{abstract}

Keywords: LIBs, microwave-assisted method, semiconductor, SIBs.

\section{INTRODUCTION}

Global warming and ever-growing energy consumption have become the focus of global concern. Development of electrochemical energy storage systems such as rechargeable batteries (lithium/sodium ion batteries, LIBs/SIBs) is considered as a promising choice to solve the energy crisis owing to their high capacity, long cycle life, and environmental friendliness [1-3]. Currently, most of the commercial cells use carbonaceous materials such as electrode materials. However, using carbonaceous material electrode limits the possibility of extracting higher energy density from the battery, which cannot satisfy the requirements of practical application [4]. Therefore, exploring other electrode materials with high specific capacity and excellent cycling stability for SIBs and LIBs remains a great challenge.

Recently, semiconductor nanostructures have attracted much attention due to their wide applications such as energy storage devices. Investigations have been carried out to prepare the semiconductor nanostructures via the conventional methods such as hydrothermal/solvothermal, sol-gel, coprecipitation, and surfactant-assisted methods for energy storage. However, they have several disadvantages such as high temperature, long reaction time, high energy consumption, nonuniform reaction conditions or requirement of special conditions [5]. Recently, microwave-assisted synthesis

\footnotetext{
*Address correspondence to these authors at the Institute of Coordination Bond Metrology and Engineering, College of Materials Science and Engineering, China Jiliang University, Hangzhou 310018, P.R. China; Tel: +86 0571 86872475; Fax: +860571 86872475; E-mail: 1xj669635@126.com; **Electrical and Electronic Engineering, Parkville, University of Melbourne 3010 Australia; Tel: +61 383443819; Fax: +61 383447412; E-mail: Shiqiang.li@unimelb.edu.au
}

has attracted great interest due to its rapid heating means [6]. Microwave irradiation as an inexpensive, quick, clean, and versatile technique can facilitate mass production in a short time with little energy consumption and form an intimate contact between the components [7-10]. Many semiconductor nanomaterials with different morphologies such as nanorods, nanowires, nanofibers, nanotubes, nanosheets and nanoparticles have been synthesized by the microwaveassisted method [11-23].

In this work, we highlight the recent progress in exploring various semiconductor nanomaterials via a microwaveassisted method. Application of these semiconductor nanomaterials in the energy storage for LIBs and SIBs is also demonstrated.

\section{PRINCIPLES OF MICROWAVE-ASSISTED SYN- THESIS}

Microwave irradiation is electromagnetic radiation with the frequency range of $0.3 \sim 300 \mathrm{GHz}$, corresponding to wavelengths of $1 \mathrm{~mm} \sim 1 \mathrm{~m}$. The industrial and domestic microwave apparatus for heating operates at a wavelength of $12.2 \mathrm{~cm}$, corresponding to a frequency of $2.45 \mathrm{GHz}$ to avoid the interference with telecommunication and microwave radar equipment. Microwave heating technology has been used for the synthesis of ceramic materials in 1975. The heating mechanism involves dipolar polarization and ionic conduction processes. The dipoles in the reaction mixture are involved in the dipolar polarization effect, and the charged particles in a sample contribute to ionic conduction [21,24]. Microwave irradiation induces interaction of the dipole moment of polar molecules or molecular ionic aggregates with alternating electronic and magnetic fields, causing molecu- 
lar-level heating which leads to homogeneous and quick thermal reactions with low thermal gradient $[25,26]$. In microwave irradiation process, the factors such as solvent type, concentration, and geometry of reaction vessel can influence the uniform and reproducible heating. The different solvents have different abilities to generate heat under microwave irradiation [27]. The ability of a given solvent to convert microwave energy into heat can be described by the loss tangent $\left(\tan \delta=\varepsilon^{\prime \prime} / \varepsilon^{\prime}\right)$, where $\varepsilon^{\prime \prime}$ is the loss factor, indicative of the efficiency with which the electromagnetic radiation is converted into heat, and $\varepsilon^{\prime}$ is the dielectric constant describing the ability of a dielectric material to store electrical potential energy in the electric field. Solvents can be divided into high $(\tan \delta>0.5)$, medium ( $\tan \delta$ 0.1-0.5), and low microwave absorbing $(\tan \delta$ $<0.1$ ) ones [28]. A reaction medium with high loss factor is required for efficient absorption and rapid heating [29]. For example, ethanol has a higher loss tangent, thus shows better the microwave absorption, leading to a more rapid heating [27]. Compared with other conventional heating methods, microwave synthesis has been considered as an efficient method for higher heating rate and selectivity, improved reproducibility, lower reaction temperature, less reaction time, and automatization and high throughput synthesis [3032].

\section{MICROWAVE-ASSISTED SYNTHESIS OF SEMI- CONDUCTOR NANOMATERIALS FOR LIBs/SIBs}

LIBs are composed of three major components: cathode, anode, and electrolyte (Fig. 1). The energy capacity is related to the properties of electrode materials. Currently, the graphite is frequently used in the anode materials for LIBs owing to its long cycle life, low cost and abundant material supply. $\mathrm{Li}$ ions are extracted from cathode and simultaneously inserted into the graphite anode, coupling with negatively charged electrons to keep overall charge neutrality [32] during the charging process. During the discharging process, $\mathrm{Li}$ ions are reversibly extracted from the anode and simultaneously inserted into the cathode [32]. However, the use of graphite anode electrode limits the possibility of extracting higher energy density from the battery, which cannot satisfy

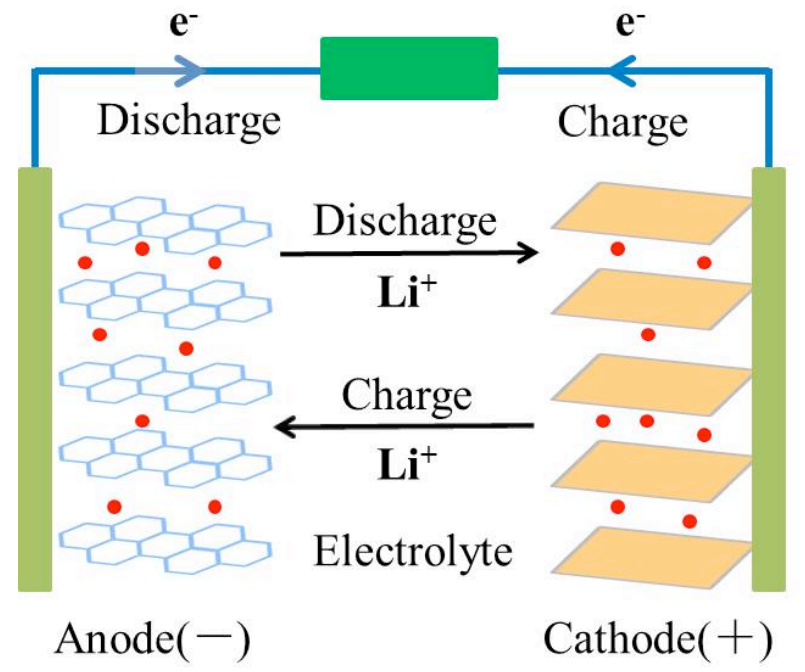

Fig. (1). Schematic representation of the most commonly used LIBs based on anodes and cathodes. the requirements of practical application. Furthermore, the high cost and possible supply risk of Li terrestrial reserves have gained more attention. As a potential alternative, SIBs have recently attracted much attention due to the abundance of sodium resources, lower cost, relatively low toxicity of sodium, and the similar chemistry between sodium and lithium. Unfortunately, the diameter of sodium ion is about $55 \%$ larger than that of the Li ion, and only a few host materials for LIBs are suitable to allow the sodium ion intercalation and deintercalation. Therefore, exploring electrode materials with high specific capacity and good cycling stability for LIBs/SIBs remains a great challenge.

Intensive efforts have been made to explore new electrode materials involving alloy [33] and semiconductor materials [34] with enhanced charge capacity, high energy density, long cycle life and environmental stability for LIBs/SIBs. Semiconductor materials prepared by microwave assisted method such as $\mathrm{TiO}_{2}, \mathrm{SnO}_{2}, \mathrm{Fe}_{2} \mathrm{O}_{3}$ et al., have been envisaged as anode materials owing to their high surface area, porosity, etc. In contrast to graphite materials, lithium storage in semiconductor materials such as $\mathrm{Fe}_{2} \mathrm{O}_{3}$ is mainly achieved via a reversible conversion reaction, by forming $\mathrm{Fe}$ nanoparticles dispersed in $\mathrm{Li}_{2} \mathrm{O}$ matrix [35]. Unfortunately, they suffer from poor cycling performance due to the large volume changes and serious aggregation of particles during repeated Li insertion and extraction reactions [36]. Reducing the size and constructing open channels in the electrode materials have been suggested to overcome the aforementioned problems [37, 38]. Recently, nanostructured materials have attracted much interest because of their novel physical and chemical properties compared to those of their bulk counterparts. Nanostructured semiconductor can accommodate the strain during cycling, and reduce the diffusion pathway for electronic/ionic transport, leading to the excellent power density. Another attractive strategy is to design and develop hybrid electrode materials based on carbon matrix such as carbon nanotubes, carbon fiber and graphene, which not only maintain the structural integrity of the composite electrode by preventing large volume changes and particle agglomeration but also increase the conductivity [39]. In this section, we summarize various semiconductor nanomaterials via a microwave assisted synthesis for LIBs/SIBs. They show the improved electrochemical performance compared with the ones synthesized via conventional methods.

\subsection{Semiconductor Oxide}

$\mathrm{TiO}_{2}$

$\mathrm{TiO}_{2}$ with a theoretical capacity of $335 \mathrm{mAh} / \mathrm{g}$ is considered as the most promising candidate for LIBs due to its high operating voltage $\left(\sim 1.5 \mathrm{~V}\right.$ vs $\left.\mathrm{Li} / \mathrm{Li}^{+}\right)$, excellent safety characteristics, abundance, and nontoxicity [40, 41]. Many research groups have carried out to study the $\mathrm{TiO}_{2}$ nano/microstructures such as nanosheets, hollow nanostructures, nanowires, nanotubes, nanospindles, and quantum dot for LIBs [40].

Single-crystal-like $\mathrm{TiO}_{2}$ with honey-like pores shows the large surface area and excellent structural durability, which is favorable for shortening the diffusion length of ion transport and reducing volumetric change. Zhang et al. [3] fabricated the single-crystal like anatase $\mathrm{TiO}_{2}$ with "honeycomb" 
porous structure via a microwave assisted approach using a microwave digestion system (Ethos TC, Milestone) at 150 ${ }^{\circ} \mathrm{C}$ for $90 \mathrm{~min}$. Field emission scanning electron microscopy (FESEM) images (Fig. 2a, b) show that the prepared $\mathrm{TiO}_{2}$ shows the honeycomb-like nanosphere with open porous structure. The average diameter of prepared $\mathrm{TiO}_{2}$ is $700 \mathrm{~nm}$. Transmission electron microscopy (TEM) images (Fig. 2c,d) show a core-corona architecture, and the core is much denser than the corona, indicating the formation of dense core and porous surface. Such single crystal-like porous anatase $\mathrm{TiO}_{2}$ shows high surface area, large internal voids, and robust structure, which grants more lithium insertion sites, larger space to buffer the volume change, and reduced effective lithium ion diffusion distance during the charge-discharge process. The as-prepared $\mathrm{TiO}_{2}$ exbihited a charge capacity of $155.8 \mathrm{mAh} / \mathrm{g}$ at a current density of $200 \mathrm{~mA} / \mathrm{g}$, and a high columbic efficiency of $99.8 \%$ in the first cycle. A capacity of $100 \mathrm{mAh} / \mathrm{g}$ can still be delivered after 100 cycles at a current density of $1000 \mathrm{~mA} / \mathrm{g}$. Therefore, the porous anatase $\mathrm{TiO}_{2}$ single crystal architectures showed stable cyclability at high current density, better reversibility, and high Coulombic efficiency for lithium storage.

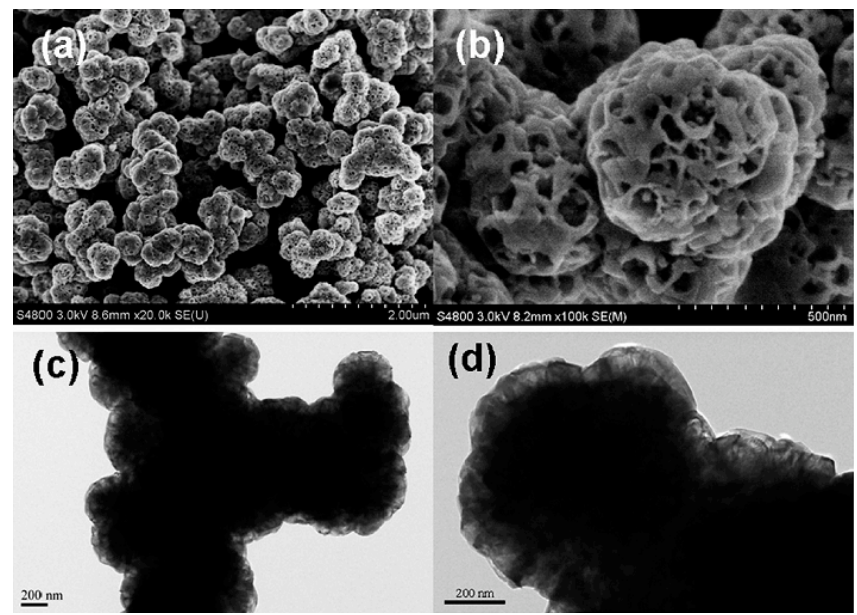

Fig. (2). FESEM images (a,b) and TEM images (c,d) of porous $\mathrm{TiO}_{2}$ single crystals obtained after 90 min microwave irradiation [3]. (Reprinted with permission from ref. [3]. Copyright (2012) American Chemical Society).

Yoon et al. [4] further prepared the anatase, rutile, and brookite of $\mathrm{TiO}_{2}$ via a facile microwave assisted solvothermal process without surfactants in an Anton Paar microwave synthesis (Synthos-3000) with a power of 600 $\mathrm{W}$ at $190{ }^{\circ} \mathrm{C}$ for $30 \mathrm{~min}$, employing $\mathrm{TiCl}_{4}$ or $\mathrm{TiCl}_{3}$ as precursors in various alcohol. The morphology, crystal structure, and crystallite size of $\mathrm{TiO}_{2}$ are related to the $\mathrm{Ti} / \mathrm{Cl}$ ion concentration, reaction $\mathrm{pH}$, and size of the alcohol molecule. The rutile $\mathrm{TiO}_{2}$ spheres synthesized using $\mathrm{TiCl}_{4}$ in octanol exhibited the best electrochemical performance with a capacity of $>200 \mathrm{mAh} / \mathrm{g}$ at a current density of 30 $\mathrm{mA} / \mathrm{g}$ after 100 cycles and high rate capability due to the nanorod-building morphology and mesoporosity of $\mathrm{TiO}_{2}$ spheres, which can provide the good electrical contact, accommodates the strain smoothly, and facilitates facile lithium ion diffusion.
$\mathrm{SnO}_{2}$

Owing to the high theoretical specific capacity of 782 $\mathrm{mAh} / \mathrm{g}$ of $\mathrm{SnO}_{2}$, it has attracted much interest as a promising anode material for LIBs. Wang et al. [6] synthesized the porous $\mathrm{SnO}_{2}$ nanotubes by a rapid microwave-assisted hydrothermal method in a microwave system (CEM Discover SGlass) at $150{ }^{\circ} \mathrm{C}$ for $30 \mathrm{~min}$ followed by annealing at $500^{\circ} \mathrm{C}$ for $1 \mathrm{~h}$ in air. As shown in Fig. (3a and b), the $\mathrm{SnO}_{2}$ shows the short tubes morphology with length, diameter, and wall thickness ranging from 0.5 to $1.5 \mu \mathrm{m}, 200$ to $400 \mathrm{~nm}$, and 50 to $100 \mathrm{~nm}$, respectively. The $\mathrm{SnO}_{2}$ nanotubes comprise interconnected nanocrystals of $\sim 8 \mathrm{~nm}$ in diameter along with abundant mesopores formed among adjacent nanocrystals (Fig. (3e and f). The $\mathrm{SnO}_{2}$ nanotubes showed the charge capacity of $1258 \mathrm{mAh} / \mathrm{g}$ at $0.1 \mathrm{C}$ owing to their unique geometry and porous structure.
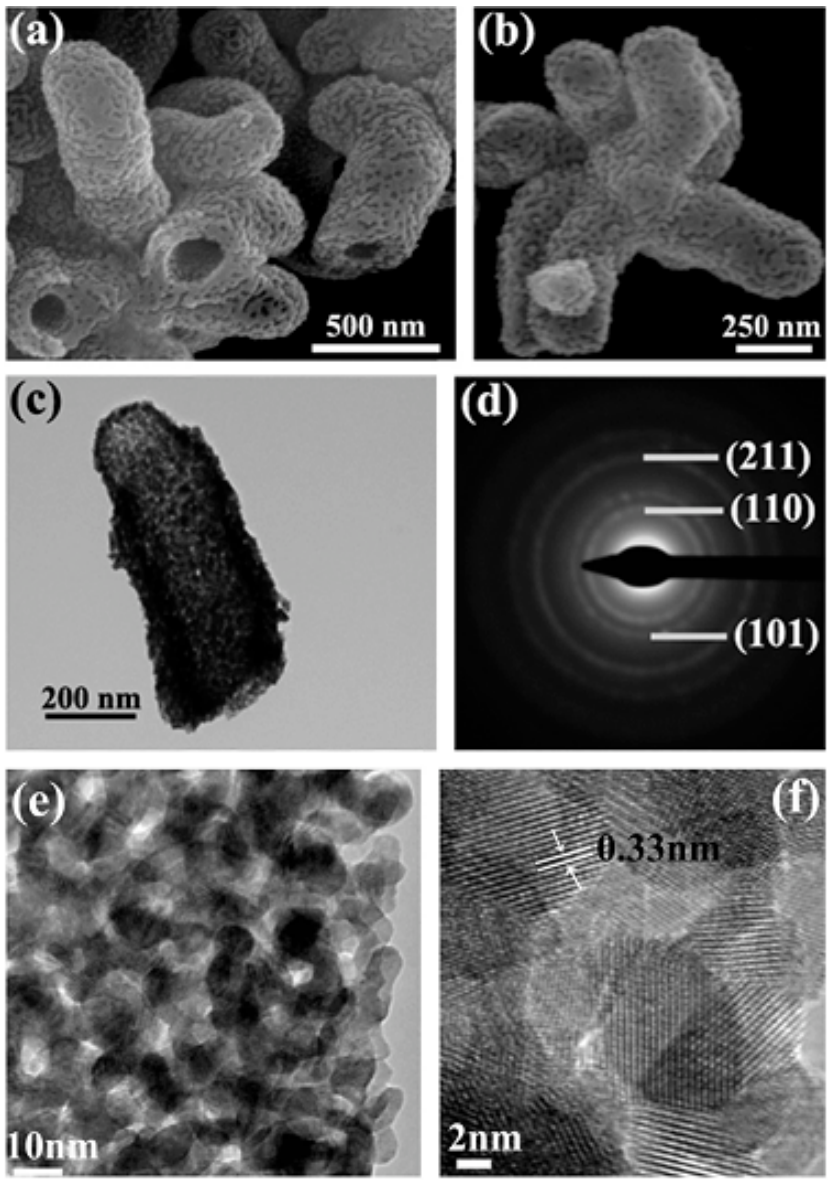

Fig. (3). (a, b) SEM images, (c) TEM image, (d) SAED pattern, (e) magnified TEM image, and (f) HRTEM image of the assynthesized $\mathrm{SnO}_{2}$ product [6]. (Reproduced with permission from ref. [6]).

Yoshinaga et al. [42] synthesized the ultrafine $\mathrm{SnO}_{2}$ nanoparticles via a microwave-assisted synthesis in a household microwave oven (Shikoku Instrumentation Co., Ltd.) at $100{ }^{\circ} \mathrm{C}$ for $5 \mathrm{~min}$. Nanosized $\mathrm{SnO}_{2}$ particles with the diameter of $5 \mathrm{~nm}$ exhibited ellipsoid shapes. $\mathrm{SnO}_{2}$ nanoparticles exhibited the initial lithium insertion capacity of 1670 $\mathrm{mAh} / \mathrm{g}$, which was significantly larger than that of a speci- 
men synthesized via the conventional method. The capacity retention of the $\mathrm{SnO}_{2}$ nanoparticles was about $60 \%$ from the 2 nd to the 50th cycle.

\section{$\mathrm{Co}_{3} \mathrm{O}_{4}$}

Recently, $\mathrm{Co}_{3} \mathrm{O}_{4}$ with special textural characteristics, such as porous $\mathrm{Co}_{3} \mathrm{O}_{4}$ nanotubes, nanowires, nanoneedles, and nanorods, has been explored as a promising anode material for LIBs due to its high capacity $(890 \mathrm{mAh} / \mathrm{g})$ [43]. Wang et al. [44] prepared the $\mathrm{Co}_{3} \mathrm{O}_{4}$ via a rapid microwaveassisted method in a microwave accelerated reaction system (MARS-5, CEM Corporation, USA) followed by thermal treatment. The porous $\mathrm{Co}_{3} \mathrm{O}_{4}$ nanowire exhibited excellent capacity retention and rate capability at high current density. The reversible capacity of $600 \mathrm{mAh} / \mathrm{g}$ could be maintained after 100 cycles at the high current density of $400 \mathrm{~mA} / \mathrm{g}$.

\section{$\mathrm{Fe}_{2} \mathrm{O}_{3}$}

Many research demonstrated that nanosized $\mathrm{Fe}_{2} \mathrm{O}_{3}$ exhibits higher capacity for LIBs, whereas it is difficult for conventional large particles to use as an active material due to an irreversible phase transition at the first discharge process [45]. Kijima et al. [46] synthesized the ultrafine $\alpha-\mathrm{Fe}_{2} \mathrm{O}_{3}$ nanoparticles via a microwave heating in a household microwave oven (Shikoku Instrumentation Co., Ltd.). The $\alpha$ $\mathrm{Fe}_{2} \mathrm{O}_{3}$ nanoparticles were used as anode in LIBs and showed good rechargeable capacity of $150 \mathrm{mAh} / \mathrm{g}$. Hematite porous $\alpha-\mathrm{Fe}_{2} \mathrm{O}_{3}$ nanostructures has a higher specific capacity of 264 $\mathrm{mAh} / \mathrm{g}$ at a higher current density of $5 \mathrm{C}$. Furthermore, in SIBs, it exhibited a reversible capacity of $300 \mathrm{mAh} / \mathrm{g}$ with excellent cycle ability and Coulombic efficiency at $0.1 \mathrm{C}$ up to 100 cycles [47].

\section{$\mathrm{NiO}$}

$\mathrm{NiO}$ has been widely used in fuel cells, solar cells, LIBs and supercapacitors owing to the high theoretical capacity $(718 \mathrm{mAh} / \mathrm{g})$, higher density $\left(6.81 \mathrm{~g} / \mathrm{cm}^{3}\right)$ than that of graphite $\left(2.268 \mathrm{~g} / \mathrm{cm}^{3}\right)$, nontoxicity and low cost [48]. Rai et al. [10] prepared the $\mathrm{NiO}$ nanoparticles by a rapid microwave-assisted method in a conventional microwave oven (MM-M 301, LG-Korea) with a power of $1000 \mathrm{~W}$ for $10 \mathrm{~min}$, followed by annealing at $600{ }^{\circ} \mathrm{C}$ in air. The $\mathrm{NiO}$ nanoparticles, which showed the irregular shaped morphology with the sizes of 50-60 $\mathrm{nm}$, had a large initial discharge capacity of $1111.08 \mathrm{mAh} / \mathrm{g}$ at $0.03 \mathrm{C}$ and retained $80 \%$ of initial capacity $(884.30 \mathrm{mAh} / \mathrm{g})$ after 20 cycles with $98 \%$ of Coulombic efficiency. More than $32 \%$ of the capacity $(253.1 \mathrm{mAh} / \mathrm{g})$ was retained even at a high current rate of 3.7 C. The enhanced electrochemical performance was due to the high specific surface area, good electric contact among the particles and easier lithium ion diffusion. The $\mathrm{NiO}$ nanorod cluster also showed a high reversible capacity of $725 \mathrm{mAh} / \mathrm{g}$ at a constant current density $(100 \mathrm{~mA} / \mathrm{g})$. The reversible capacity still maintained $584 \mathrm{mAh} / \mathrm{g}$ after 16 cycles [49].

\subsection{Semiconductor Sulfides}

$S b_{2} S_{3}$

$\mathrm{Sb}_{2} \mathrm{~S}_{3}$ is a kind of semiconductor with high photosensitivity and thermoelectric power for the application of solar en- ergy conversion and LIBs [50]. Yang et al. [51] successfully synthesized $\mathrm{Sb}_{2} \mathrm{~S}_{3}$ via microwave irradiation by the reaction of $\mathrm{SbCl}_{3}$ and $\mathrm{CS}\left(\mathrm{NH}_{2}\right)_{2}$ with PVP as the surfactant in a domestic microwave oven for $15 \mathrm{~min}$. The as-prepared $\mathrm{Sb}_{2} \mathrm{~S}_{3}$ sample showed the rod-like structure with the diameter of $30 \sim 50 \mathrm{~nm}$, and showed a large first discharge capacity of $677.89 \mathrm{mAh} / \mathrm{g}$.

\section{$\mathrm{Cu}_{2} \mathrm{ZnSnS}_{4}$}

$\mathrm{Cu}_{2} \mathrm{ZnSnS}_{4}$ (CZTS) consists of $\mathrm{Cu}, \mathrm{Zn}$, and $\mathrm{Sn}$ elements that are electrochemically active toward lithium, and thus is regarded as a promising anode material for LIBs. Yang et al. [52] reported a simple microwave-assisted method to synthesize the CZTS nanocrystals in a CEM Discover microwave reactor with a power of $220 \mathrm{~W}$ at $260{ }^{\circ} \mathrm{C} . \mathrm{Cu}\left(\mathrm{NO}_{3}\right)_{2} \cdot 3 \mathrm{H}_{2} \mathrm{O}$, $\mathrm{Zn}\left(\mathrm{NO}_{3}\right)_{2} \cdot 6 \mathrm{H}_{2} \mathrm{O}, \mathrm{SnCl}_{4} \cdot 5 \mathrm{H}_{2} \mathrm{O}$, and sulfur powder were used as starting materials. The as-prepared CZTS nanoparticles with mono-dispersed size of about $10-15 \mathrm{~nm}$ was applied as anode material for LIBs. The CZTS nanocrystals anode showed a reversible capacity of $288 \mathrm{mAh} / \mathrm{g}$ at $0.1 \mathrm{~A} / \mathrm{g}$ current density, and still maintained capacity retention of $81 \%$ after 30 cycles. The CZTS anode had a good reversibility and the structure of the electrode was stable even under high rates cycling.

\subsection{Semiconductor Composites}

Pure semiconductor suffers from poor cycling performance resulting from the huge volume changes during $\mathrm{Li}$ insertion and extraction processes, which lead to pulverization of the electrode and electrical disconnection of the active materials. Recently, an attractive option is to design and develop composite materials base on pure semiconductor to solve the problem. Many studies have been reported that embedding semiconductor in the graphene nanosheet matrix can enhance the electrochemical performance of semiconductor in LIBs/SIBs $[53,54]$. The enhanced electrochemical performance of graphene or CNTs-based composites can be attributed to the synergistic effect from the semiconductor and graphene or CNTs, which is similar to those reported results $[55,56]$. Firstly, the conductive network structure in the graphene or CNTs-based composites can ensure efficient and continuous electron transport [57, 58]. Secondly, the graphene or CNTs can act as the buffer layer to accommodate the volume expansion and prevent pulverization of pure semiconductor during charge and discharge process [57, 59]. Finally, the large surface area of the graphene or CNTsbased composites can provide a sufficient electrodeelectrolyte interface to adsorb lithium/sodium ion and facilitate the rapid charge-transfer reaction. However, excessive graphene will stick together and significantly block the channels for sodium ion diffusion, leading to the decreased electrochemical performance of graphene-based composites [60].

Qin et al. [60] reported a simple microwave-assisted method to synthesize the $\mathrm{MoS}_{2}$-graphene composites by reduction of graphene oxide in $\mathrm{MoS}_{2}$ precursor solution with maximum microwave irradiation power of $100 \mathrm{~W}$ for $10 \mathrm{~min}$ at $150{ }^{\circ} \mathrm{C}$ using a microwave system (Explorer48, CEM Co.), followed by annealing in $\mathrm{N}_{2} / \mathrm{H}_{2}$ atmosphere at $800{ }^{\circ} \mathrm{C}$ for $2 \mathrm{~h}$. As shown in Fig. (4), the $\mathrm{MoS}_{2}$ and RGO are interconnected tightly, forming a three dimensional hierarchical nanostruc- 


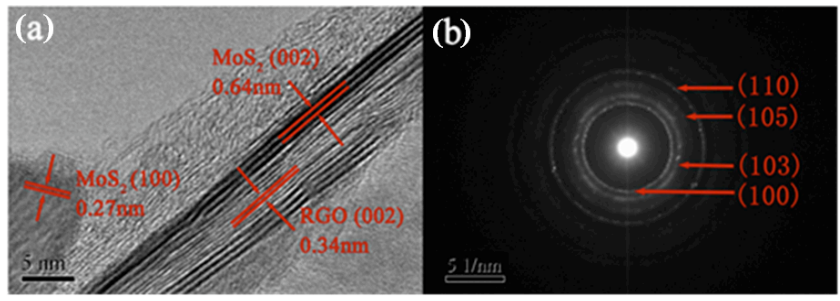

Fig. (4). (a) HRTEM image and (b) SAED pattern of $\mathrm{MoS}_{2}-$ graphene composites [60]. (Reproduced with permission from ref. [60]).

tures. This is favorable for the fast collection and conduction of electrons and diffusion of sodium ions during the chargedischarge process. At the optimum RGO loading, the $\mathrm{MoS}_{2}$ graphene composites exhibited a stable discharge capacity of about $305 \mathrm{mAh} / \mathrm{g}$ at current density of $100 \mathrm{~mA} / \mathrm{g}$ after 50 cycles.

The same group [61] also fabricated the $\mathrm{Fe}_{2} \mathrm{O}_{3}$-graphene composites via a facile microwave-assisted method using a microwave system with maximum microwave irradiation power of $100 \mathrm{~W}$ for $10 \mathrm{~min}$ at $150{ }^{\circ} \mathrm{C}$ sing a microwave system (Explorer 48, CEM Co.), and investigated as anode material for SIBs. The $\mathrm{Fe}_{2} \mathrm{O}_{3}$ nanoparticles with diameters of 4$8 \mathrm{~nm}$ are uniformly anchored on RGO sheets in the $\mathrm{Fe}_{2} \mathrm{O}_{3}$ graphene composite to form a conductive network structure (Fig. 5). As shown in Fig. (6), $\mathrm{Fe}_{2} \mathrm{O}_{3}$-graphene composite with 30 wt.\% graphene exhibits a maximum reversible capacity of $289 \mathrm{~mA} \mathrm{~h} / \mathrm{g}$ at a current density of $50 \mathrm{~mA} / \mathrm{g}$ after 50 cycles and excellent rate performance due to the synergistic effect between $\mathrm{Fe}_{2} \mathrm{O}_{3}$ and graphene. A higher capacity of $\sim 310 \mathrm{~mA} \mathrm{~h} / \mathrm{g}$ at a current density of $100 \mathrm{~mA} / \mathrm{g}$ after 150 cycles was achieved for the $\mathrm{Fe}_{2} \mathrm{O}_{3}$-graphene composites prepared by Zhang et al. [62].

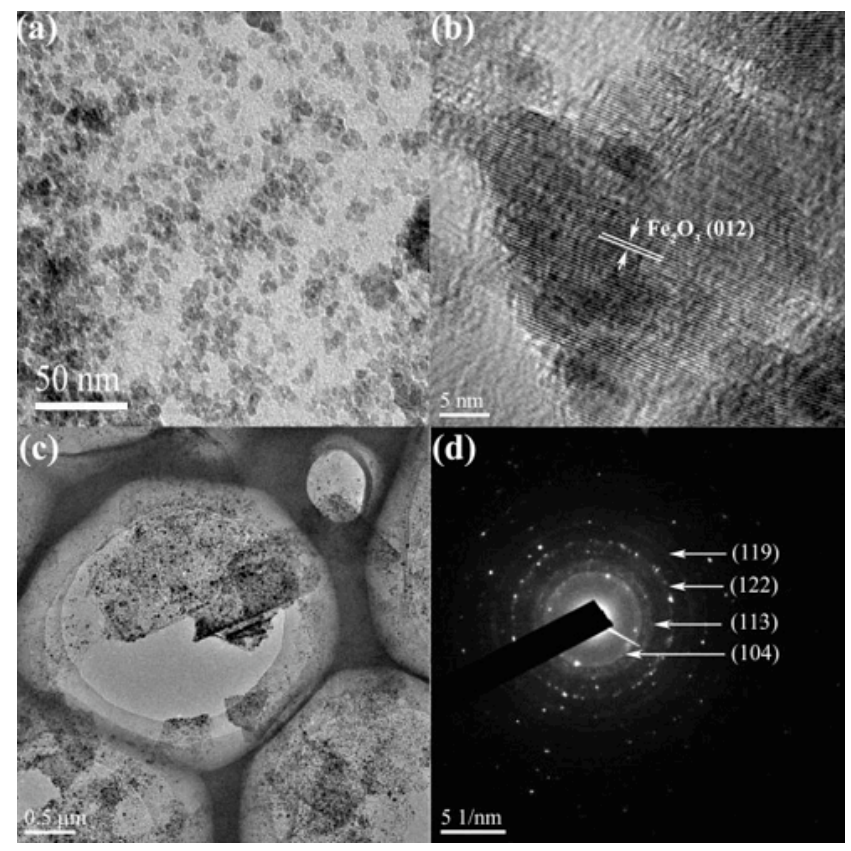

Fig. (5). HRTEM images of (a-b) $\mathrm{Fe}_{2} \mathrm{O}_{3}$ and (c) $\mathrm{Fe}_{2} \mathrm{O}_{3}$-graphene composites; (d) SAED pattern of $\mathrm{Fe}_{2} \mathrm{O}_{3}$-graphene composites [61]. (Reproduced with permission from ref. [61]).

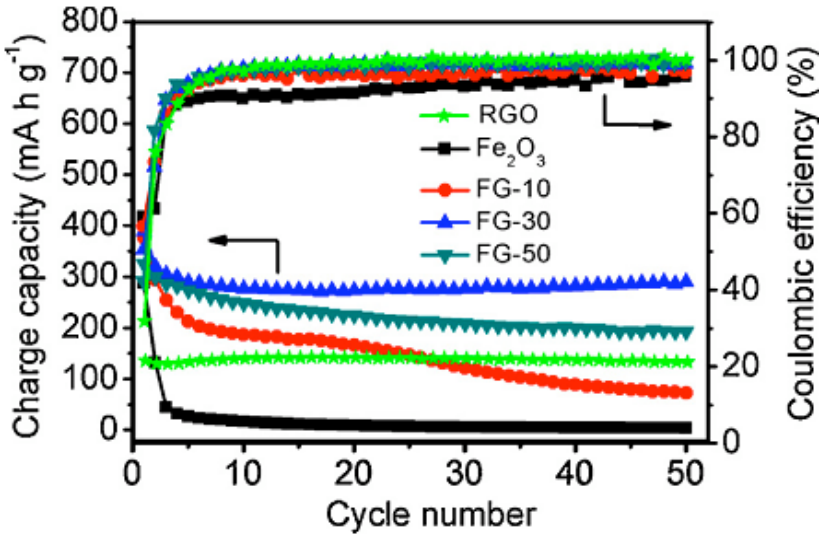

Fig. (6). Cycle performances of $\mathrm{RGO}$, and $\mathrm{Fe}_{2} \mathrm{O}_{3}$-graphene composites electrodes at a current density of $50 \mathrm{~mA} / \mathrm{g}$ [61]. (Reproduced with permission from ref. [61]).

Unfortunatley, the graphene has poor electrical conductivity, which is because that incomplete chemical reduction is frequently observed in chemically reduced graphene oxide process. Attempts to combine highly conductive carbon nanotubes (CNTs) and graphene have been reported in efforts to obtain a hybrid with superior electrochemical, electrical or catalytic properties. Therefore, the incorporation of CNTs into $\mathrm{SnO}_{2}$-graphene composites to form ternary hybrid materials should be a promising method to design advanced anode materials for LIBs. Chen et al. [63] developed a facile one-step microwave assited method to fabricate the $\mathrm{SnO}_{2}$-graphene-CNTs composites using a microwave synthesis system (Explorer-48, CEM, USA) at $150{ }^{\circ} \mathrm{C}$ with a microwave irradiation power of $100 \mathrm{~W}$ for 10 min. As shown in Fig. (7), graphene sheets show the twodimensional sheet structure with wrinkles, and $\mathrm{SnO}_{2}$ nanoparticles with diameters of 3-5 nm are densely attached to the RGO sheets. The CNT weave between RGO and $\mathrm{SnO}_{2}$ nanoparticles to build a network structure, which favors electron transfer between them. $\mathrm{SnO}_{2}$-graphene-CNTs composites with $60 \mathrm{wt} . \% \mathrm{SnO}_{2}$ showed a maximum capacity of $502 \mathrm{~mA} \mathrm{~h} / \mathrm{g}$ at $100 \mathrm{~mA} / \mathrm{g}$ after 50 cycles. A capacity of $344 \mathrm{~mA} \mathrm{~h} / \mathrm{g}$ was maintained even at a high current density of $1000 \mathrm{~mA} / \mathrm{g}$. The enhanced electrochemical performance is due to the synergistic effect of $\mathrm{SnO}_{2}, \mathrm{RGO}$ and CNTs, in which RGO sheets support $\mathrm{SnO}_{2}$ nanoparticles and CNTs act as wires conductively connecting the large RGO sheets together.

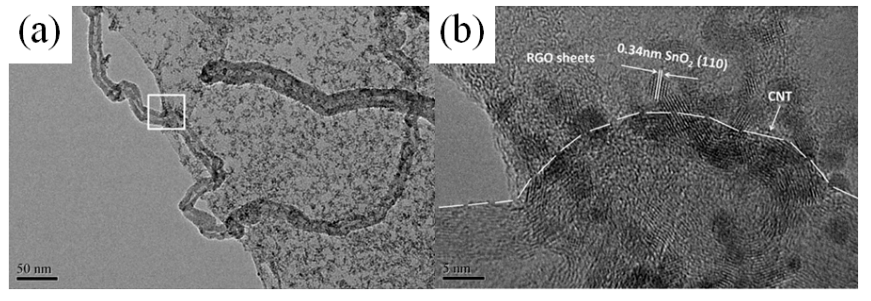

Fig. (7). TEM images of $\mathrm{SnO}_{2}$-graphene-CNTs composites [63]. (Reproduced with permission from ref. [63]).

\section{SUMMARY AND OUTLOOK}

Semiconductor materials synthesized by microwave assisted method have been reviewed for LIBs/SIBs. Compared 
with other conventional heating, microwave synthesis offers several advantages such as rapid heating, higher reaction rate and selectivity, lower reaction temperature, shorter reaction time, homogeneous thermal transmission, and phase purity with better yields due to the thermal and non-thermal effects of microwave, i.e. superheating, polarization, dielectric properties, hot spot formation, nuclear spin rotation and spin alignment [64]. However, there are several challenges remaining. One of the major drawbacks is the equipment cost. With the technique development, less expensive equipment should become available [28]. In addition, the short penetration depth of microwave irradiation into the medium limits the size of the reactor, which will limit the application of microwave in the synthesis of semiconductor nanomaterials for energy storage. Another crucial challenge is to understand the effect of microwave heating on nucleation and growth of semiconductor nanomaterials [31]. All in all, as a promising synthesis technique, microwave-assisted synthesis has been becoming more and more popular method for the preparation of semiconductor nanomaterials for the wide application of energy storage field.

\section{CONFLICT OF INTEREST}

The authors confirm that this article content has no conflict of interest.

\section{ACKNOWLEDGEMENTS}

Financial support from the National Natural Science Foundation of China (No. 21401180, 51402277, 51402274) is gratefully acknowledged.

\section{REFERENCES}

[1] Liu, F.; Song, S.Y.; Xue, D.F.; Zhang, H.J. Folded structured graphene paper for high performance electrode materials. Adv. Mater., 2012, 24, 1089-1094.

[2] Liu, Q.; Asiri, M.A.; Obaid, Y.A.; Sun, X. Polypyrrole-coated Membrane Filter: A Novel Binder-free Three-Dimensional Porous Electrode for Supercapacitors. Curr. Nanosci., 2014, 10, 705-708.

[3] Zhang, D.Q.; Wen, M.C.; Zhang, P.; Zhu, J.; Li, G.S.; Li, H.X. Microwave-induced synthesis of porous single-crystal-like $\mathrm{TiO}_{2}$ with excellent lithium storage properties. Langmuir, 2012, 28, 4543-4547.

[4] Yoon, S.; Lee, E.S.; Manthiram, A. Microwave-solvothermal synthesis of various polymorphs of nanostructured $\mathrm{TiO}_{2}$ in different alcohol media and their lithium ion storage properties. Inorg. Chem., 2012, 51, 3505-3512.

[5] Siskin, M.; Katritzky, A.R. Reactivity of organic compounds in hot water: geochemical and technological implications. Science, 1991, 254, 231-237.

[6] Wang, H.E.; Xi, L.J.; Ma, R.G.; Lu, Z.G.; Chung, C.Y.; Bello, I.; Zapien, J.A. Microwave-assisted hydrothermal synthesis of porous $\mathrm{SnO}_{2}$ nanotubes and their lithium ion storage properties. J. Solid St. Chem., 2012, 190, 104-110.

[7] Zhu, G.; Pan, L.K.; Xu, T.; Zhao, Q.; Lu, B.; Sun, Z. Microwave assisted $\mathrm{CdSe}$ quantum dot deposition on $\mathrm{TiO}_{2}$ films for dyesensitized solar cells. Nanoscale, 2011, 3, 2188-2193.

[8] Liu, X.J.; Wang, X.J.; Li, H.L.; Li, J.L.; Pan, L.K.; Zhang, J.; Min, G.Q.; Sun, Z.; Sun, C.Q. Enhanced visible light photocatalytic activity of $\mathrm{ZnO}$ doped with downconversion $\mathrm{NaSrBO}_{3}: \mathrm{Tb}^{3+}$ phosphors Dalton Trans., 2015, 44, 97-103.

[9] Liu, X.J.; Pan, L.K.; Lv, T.; Sun, Z. CdS sensitized $\mathrm{TiO}_{2}$ film for photocatalytic reduction of $\mathrm{Cr}$ (VI) by microwave-assisted chemical bath deposition method. J. Alloys Compd., 2014, 583, 390-395.
[10] Kumar, R.A.; Tuan, A.L.; Park, C.J.; Kim, J. Electrochemical study of $\mathrm{NiO}$ nanoparticles electrode for application in rechargeable lithium-ion batteries. Ceram. Int., 2013, 39, 6611-6618.

[11] Schwenke, A.M.; Stumpf, S.; Hoeppener, S.; Schubert, U.S. FreeStanding Carbon Nanofibrous Films Prepared by a Fast Microwave-Assisted Synthesis Process. Adv. Funct. Mater., 2014, 24, 1602-1608.

[12] Mondal, A.K.; Su, D.; Chen, S.; Kretschmer, K.; Xie, X.; Ahn, H.J.; Wang, G.A Microwave Synthesis of Mesoporous $\mathrm{NiCo}_{2} \mathrm{O}_{4}$ Nanosheets as Electrode Materials for Lithium-Ion Batteries and Supercapacitors. ChemPhysChem, 2015, 16, 169-175.

[13] Yang, D.P.; Gao, F.; Cui, D.X.; Yang, M. Microwave rapid synthesis of nanoporous $\mathrm{Fe}_{3} \mathrm{O}_{4}$ magnetic microspheres. Curr. Nanosci., 2009, 5, 485-488.

[14] Wang, W.W.; Zhu, Y.J. Microwave-Assisted Synthesis of Magnetite Nanosheets in Mixed Solvents of Ethylene Glycol and Water. Curr. Nanosci., 2007, 3, 171-176.

[15] Sharma, S.; Thakur, M.; Deb, M.K. Preparation of silver nanoparticles by microwave irradiation. Curr. Nanosci., 2008, 4, 138-140.

[16] Asghari, M.; Ghasemi, A.; Paimozed, E. Microwave and magnetic analysis of substituted $\mathrm{SrFe}_{12} \mathrm{O}_{19} /$ multi-walled carbon nanotubes. Curr. Nanosci., 2012, 8, 239-243.

[17] Liu, X.J.; Pan, L.K.; Li, J.L.; Yu, K.; Sun, Z.; Sun, C.Q. Light down-converting characteristics of $\mathrm{ZnO}-\mathrm{Y}_{2} \mathrm{O}_{2} \mathrm{~S}: \mathrm{Eu}^{3+}$ for visible light photocatalysis. J. Colloid Interface Sci., 2013, 404, 150-154.

[18] Liu, X.J.; Pan, L.K.; Chen, T.Q.; Li, J.L.; Yu, K.; Sun, Z.; Sun, C.Q. Visible light photocatalytic degradation of methylene blue by $\mathrm{SnO}_{2}$ quantum dots prepared via microwave-assisted method. Catal. Sci. Technol., 2013, 3, 1805-1809.

[19] Liu, X.J.; Wang, X.J.; Li, H.L.; Pan, L.K.; Lv, T.; Sun, Z.; Sun, C.Q. Microwave-assisted synthesis of $\mathrm{ZnO}-\mathrm{Y}_{3} \mathrm{Al}_{5} \mathrm{O}_{12}: \mathrm{Ce}^{3+}$ composites with enhanced visible light photocatalysis. J. Mater. Chem., 2012, 22, 16293-16298.

[20] Chen, T.Q.; Liu, Y.; Pan, L.K.; Lu, T.; Yao, Y.F.; Sun, Z.; Chua, D.H.C.; Chen, Q. Electrospun carbon nanofibers as anode materials for sodium ion batteries with excellent cycle performance. $J$. Mater. Chem. A, 2014, 2, 4117-4121.

[21] Chen, T.Q.; Pan, L.K.; Loh, T.A.J.; Chua, D.H.C.; Yao, Y.F.; Chen, Q.; Li, D.S.; Qin, W.; Sun, Z. Porous nitrogen-doped carbon microspheres as anode materials for lithium ion batteries. Dalton Trans., 2014, 43, 14931-14935.

[22] Chen, T.Q.; Pan, L.K.; Lu, T.; Fu, C.L.; Chua, D.H.C.; Sun, Z. Fast synthesis of carbon microspheres via a microwave-assisted reaction for sodium ion batteries. J. Mater. Chem. A, 2014, 2, 1263-1267.

[23] Chen, T.Q.; Pan, L.K.; Yu, K.; Sun, Z. Microwave-assisted synthesis of reduced graphene oxide-carbon nanotube composites as negative electrode materials for lithium ion batteries. Solid State Ionics, 2012, 229, 9-13.

[24] Baghbanzadeh, M.; Carbone, L.; Cozzoli, P.D.; Kappe, C.O Microwave-Assisted Synthesis of Colloidal Inorganic Nanocrystals. Angew. Chem. Int. Ed., 2011, 50, 11312-11359.

[25] Dahal, N.; García, S.; Zhou, J.; Humphrey, S. M. Beneficial Effects of Microwave-Assisted Heating versus Conventional Heating in Noble Metal Nanoparticle Synthesis. ACS Nano, 2012, 6, 94339446.

[26] Zhong, C.; Wang, J.Z.; Chen, Z.X.; Liu, H.K. $\mathrm{SnO}_{2}$-graphene composite synthesized via an ultrafast and environmentally friendly microwave autoclave method and its use as a superior anode for lithium-ion batteries. J. Phys. Chem. C, 2011, 115, 25115-25120.

[27] Lidstrom, P.; Tierney, J.; Wathey, B.; Westman, J. Microwave assisted organic synthesis-a review. Tetrahedron, 2001, 57, 92259283.

[28] Kappe, C.O. Controlled microwave heating in modern organic synthesis. Angew. Chem. Int. Ed., 2004, 43, 6250-6284.

[29] Park, S.H.; Lee, W.J. Coaxial carbon nanofiber/NiO core-shell nanocables as anodes for lithium ion batteries. RSC $A d v$., 2015, 5 , 23548-23555.

[30] Kappe, C.O. Microwave dielectric heating in synthetic organic chemistry. Chem. Soc. Rev., 2008, 37, 1127-1139.

[31] Bilecka, I.; Niederberger, M. Microwave chemistry for inorganic nanomaterials synthesis. Nanoscale, 2010, 2, 1358-1374.

[32] Jiang, C.; Hosono, E.; Zhou, H. Nanomaterials for lithium ion batteries. Nano Today, 2006, 1, 28-33.

[33] Farbod, B.; Cui, K.; Kalisvaart, W.P.; Kupsta, M.; Zahiri, B.; Kohandehghan, A.; Lotfabad, E.M.; Li, Z.; Luber, E.J.; Mitlin, D. 
Anodes for Sodium Ion Batteries Based on Tin-GermaniumAntimony Alloys. ACS Nano, 2014, 8, 4415-4429.

[34] Yuan, S.; Huang, X.L.; Ma, D.L.; Wang, H.G.; Meng, F.Z.; Zhang, X.B. Engraving Copper Foil to Give Large-Scale Binder-Free Porous $\mathrm{CuO}$ Arrays for a High-Performance Sodium-Ion Battery Anode. Adv. Mater., 2014, 26, 2273-2279.

[35] Philippe, B.; Valvo, M.; Lindgren, F.; Rensmo, H.; Edstrom, K. Investigation of the Electrode/Electrolyte Interface of $\mathrm{Fe}_{2} \mathrm{O}_{3}$ Composite Electrodes: Li vs Na Batteries. Chem. Mater., 2014, 26, 5028-5041.

[36] Xu, S.M.; Hessel, C.M.; Ren, H.; Yu, R.B.; Jin, Q.; Yang, M.; Zhao, H.J.; Wang, D. $\alpha-\mathrm{Fe}_{2} \mathrm{O}_{3}$ multi-shelled hollow microspheres for lithium ion battery anodes with superior capacity and charge retention. Energy Environ. Sci., 2014, 7, 632-637.

[37] Koo, B.; Chattopadhyay, S.; Shibata, T.; Prakapenka, V.B.; Johnson, C.S.; Rajh, T.; Shevchenko, E.V. Intercalation of Sodium Ions into Hollow Iron Oxide Nanoparticles. Chem. Mater., 2013, 25, 245-252.

[38] Jiang, Y.Z.; Hu, M.J.; Zhang, D.; Yuan, T.Z.; Sun, W.P.; Xu, B.; Yan, M. Transition metal oxides for high performance sodium ion battery anodes. Nano Energy, 2014, 5, 60-66.

[39] Wu, M.H.; Chen, J.; Wang, C.; Wang, F.Q.; Yi, B.L.; Su, W.; Wei, Z.F.; Liu, S.N. Facile Synthesis of $\mathrm{Fe}_{2} \mathrm{O}_{3}$ Nanobelts/CNTs Composites as High-performance Anode for Lithium-ion Battery. Electrochim. Acta, 2014, 132, 533-537.

[40] Luo, J.; Xia, X.; Luo, Y.; Guan, C.; Liu, J.; Qi, X.; Ng, C.F.; Yu, T.; Zhang, H.; Fan, H.J. Rationally designed hierarchical $\mathrm{TiO}_{2} @ \mathrm{Fe}_{2} \mathrm{O}_{3}$ hollow nanostructures for improved lithium ion storage. Adv. Energy Mater., 2013, 3, 737-743.

[41] Liao, J.Y.; Higgins, D.; Lui, G.; Chabot, V.; Xiao, X.; Chen, Z. Multifunctional $\mathrm{TiO}_{2}-\mathrm{C} / \mathrm{MnO}_{2}$ core-double-shell nanowire arrays as high-performance 3D electrodes for lithium ion batteries. Nano Lett., 2013, 13, 5467-5473.

[42] Yoshinaga, M.; Kijima, N.; Wakahara, S.; Akimoto, J. Microwave Synthesis and Electrochemical Properties of Ultrafine $\mathrm{SnO}_{2}$ Nanoparticles. Chem. Lett., 2011, 40, 414-416.

[43] Wang, J.; Yang, N.; Tang, H.; Dong, Z.; Jin, Q.; Yang, M.; Kisailus, D.; Zhao, H.; Tang, Z.; Wang, D. Accurate control of multishelled $\mathrm{Co}_{3} \mathrm{O}_{4}$ hollow microspheres as high-performance anode materials in lithium-ion batteries. Angew. Chem., 2013, 125, 6545-6548.

[44] Wang, J.; Niu, B.; Du, G.; Zeng, R.; Chen, Z.; Guo, Z.; Dou, S. Microwave homogeneous synthesis of porous nanowire $\mathrm{Co}_{3} \mathrm{O}_{4}$ arrays with high capacity and rate capability for lithium ion batteries. Mater. Chem. Phys., 2011, 126, 747-754.

[45] Zheng, C.F.; Meng, N.; Chen, Q. Nano Electrochemical Reactors of $\mathrm{Fe}_{2} \mathrm{O}_{3}$ Nanoparticles Embedded in Shells of Nitrogen-doped Hollow Carbon Spheres as High-Performance Anodes for LithiumIon Batteries. Nanoscale, 2015.

[46] Kijima, N.; Yoshinaga, M.; Awaka, J.; Akimoto, J. Microwave synthesis, characterization, and electrochemical properties of $\alpha$ $\mathrm{Fe}_{2} \mathrm{O}_{3}$ nanoparticles. Solid State Ionics, 2011, 192, 293-297.

[47] Rao, B.N.; Kumar, P.R.; Padmaraj, O.; Venkateswarlu, M.; Satyanarayana, N. Rapid microwave assisted hydrothermal synthesis of porous $\alpha-\mathrm{Fe}_{2} \mathrm{O}_{3}$ nanostructures as stable and high capacity negative electrode for lithium and sodium ion batteries. RSC Adv., 2015, 5, 34761-34768.

[48] Nattestad, A.; Mozer, A.J.; Fischer, M.K.; Cheng, Y.B.; Mishra, A.; Bäuerle, P.; Bach, U. Highly efficient photocathodes for dyesensitized tandem solar cells. Nat. Mater., 2010, 9, 31-35.

[49] Zou, Y.; Wang, Y. Microwave-assisted synthesis of porous nickel oxide nanostructures as anode materials for lithium-ion batteries. Rare Metals, 2011, 30, 59-62.
[50] Denis, Y.; Prikhodchenko, P.V.; Mason, C.W.; Batabyal, S.K.; Gun, J.; Sladkevich, S.; Medvedev, A.G.; Lev, O. High-capacity antimony sulphide nanoparticle-decorated graphene composite as anode for sodium-ion batteries. Nat. commun., 2013, 4, 2922.

[51] Yang, H.; Su, X.; Tang, A. Microwave synthesis of nanocrystalline $\mathrm{Sb}_{2} \mathrm{~S}_{3}$ and its electrochemical properties. Mater. Res. Bull., 2007, 42, 1357-1363.

[52] Yang, X.; Xu, J.; Xi, L.; Yao, Y.; Yang, Q.; Chung, C.; Lee, C.-S. Microwave-assisted synthesis of $\mathrm{Cu}_{2} \mathrm{ZnSnS}_{4}$ nanocrystals as a novel anode material for lithium ion battery. J. Nanopart. Res., 2012, 14, 1-6.

[53] Wang, H.L.; Yang, Y.; Liang, Y.Y.; Cui, L.F.; Sanchez Casalongue, H.; Li, Y.; Hong, G.S.; Cui, Y.; Dai, H.J. LiMn ${ }_{x} \mathrm{Fe}_{\mathrm{x}} \mathrm{PO}_{4}$ Nanorods Grown on Graphene Sheets for Ultrahigh-RatePerformance Lithium Ion Batteries. Angew. Chem., 2011, 123, $7502-7506$.

[54] Wu, Z.S.; Zhou, G.; Yin, L.C.; Ren, W.; Li, F.; Cheng, H.M. Graphene/metal oxide composite electrode materials for energy storage. Nano Energy, 2012, 1, 107-131.

[55] Zheng, M.B.; Qiu, D.F.; Zhao, B.; Ma, L.Y.; Wang, X.R.; Lin, Z.X.; Pan, L.J.; Zheng, Y.D.; Shi, Y. Mesoporous iron oxide directly anchored on a graphene matrix for lithium-ion battery anodes with enhanced strain accommodation. $R S C A d v ., 2013,3$, 699-703.

[56] Kim, I.T.; Magasinski, A.; Jacob, K.; Yushin, G.; Tannenbaum, R. Synthesis and electrochemical performance of reduced graphene oxide/maghemite composite anode for lithium ion batteries. Carbon, 2013, 52, 56-64.

[57] Jian, Z.L.; Zhao, B.; Liu, P.; Li, F.J.; Zheng, M.B.; Chen, M.W.; Shi, Y.; Zhou, H.S. $\mathrm{Fe}_{2} \mathrm{O}_{3}$ nanocrystals anchored onto graphene nanosheets as the anode material for low-cost sodium-ion batteries. Chem. Commun., 2014, 50, 1215-1217.

[58] Wang, W.; Hu, L.W.; Ge, J.B.; Hu, Z.Q.; Sun, H.B.; Sun, H.; Zhang, H.Q.; Zhu, H.M.; Jiao, S.Q. In Situ Self-Assembled

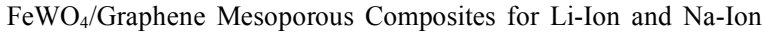
Batteries. Chem. Mater., 2014, 26, 3721-3730.

[59] Qu, B.H.; Ma, C.Z.; Ji, G.; Xu, C.H.; Xu, J.; Meng, Y.S.; Wang, T.H.; Lee, J.Y. Layered $\mathrm{SnS}_{2}$-Reduced Graphene Oxide Composite-A High-Capacity, High-Rate, and Long-Cycle Life Sodium-Ion Battery Anode Material. Adv. Mater., 2014, 26, 38543859

[60] Qin, W.; Chen, T.Q.; Pan, L.K.; Niu, L.Y.; Hu, B.W.; Li, D.S.; Li, J.L.; Sun, Z. MoS ${ }_{2}$-reduced graphene oxide composites via microwave assisted synthesis for sodium ion battery anode with improved capacity and cycling performance. Electrochim. Acta, 2015, 153, 55-61.

[61] Liu, X.J.; Chen, T.Q.; Chu, H.P.; Niu, L.Y.; Sun, Z.; Pan, L.; Sun, C.Q. $\mathrm{Fe}_{2} \mathrm{O}_{3}$-reduced graphene oxide composites synthesized via microwave-assisted method for sodium ion batteries. Electrochim. Acta, 2015, 166, 12-16.

[62] Zhang, Z.J.; Wang, Y.X.; Chou, S.L.; Li, H.J.; Liu, H.K.; Wang, J.Z. Rapid synthesis of $\alpha-\mathrm{Fe}_{2} \mathrm{O}_{3} / \mathrm{rGO}$ nanocomposites by microwave autoclave as superior anodes for sodium-ion batteries. J. Power Sources, 2015, 280, 107-113.

[63] Chen, T.Q.; Pan, L.K.; Liu, X.J.; Yu, K.; Sun, Z. One-step synthesis of $\mathrm{SnO}_{2}$-reduced graphene oxide-carbon nanotube composites via microwave assistance for lithium ion batteries. RSC $A d v ., 2012,2,11719-11724$.

[64] Remya, N.; Lin, J.G. Current status of microwave application in wastewater treatment-a review. Chem. Eng. J., 2011, 166, 797-813. 